\title{
IMPLEMENTASI VISI SUSTAINABLE DEVELOPMENT GOALS(SDGs) PADA PROGRAM BERBASIS MASYARAKAT DI ERA PANDEMI
}

\author{
Bahrul Jalaali \\ Departemen Teknik Mesin Sekolah Tinggi Teknologi Adisutjipto \\ Jalan Janti Blok. R, Lanud Adisutjipto, Karang Janbe, Banguntapan, Kec. Banguntapan, \\ Bantul, Daerah Istimewa Yogyakarta 55198 \\ Email: Bahrul@stta.ac.id
}

Received : July $2^{\text {nd }}, 2020$; Accepted : August $3^{\text {rd }}, 2020$; Published : January $1^{\text {st }}, 2021$

\begin{abstract}
Abstrak
Pandemi COVID-19 telah memberikan dampak langsung baik dalam bidang kesehatan maupun kondisi perekonomian khususnya di Indonesia. Sebuah sinergitas antara perguruan tinggi, masyarakat dan praktisi diperlukan dalam upaya pencegahan COVID-19 serta membantu perputaran roda perekonomian dalam bentuk kegiatan pengabdian kepada masyarakat. Sustainable development goals (SDGs) merupakan program aksi global yang akan dijadikan acuan bentuk kegiatan pengabdian masyarakat. Analisis indikator ketercapainya tujuan global dengan hasil luaran program berbasis masyarakat yang telah dilakukan untuk memberikan rekomendasi arahan program sehingga dapat menyelesaikan permasalahan sekitar dengan orientasi global. Dalam wujud tridarma perguruan tinggi, kegiatan pengabdian masyarakat berbasis SDGs telah diimplementasikan ke daerah terdampak COVID-19 yakni skala usaha mikro-kecil dan menengah (UMKM) konveksi di Wedi, Klaten dan distribusi alat kesehatan ke RSUD Wonosari. Evaluasi program akan dilakukan dalam dimensi ethical, social dan economical berikut intepretasi hasilnya Dari hasil kegiatan pengabdian dapat dikatakan tercapainya keselarasan kegiatan pengabdian masyarakat dengan misi SDGs pada implementasi dalam bidang ekonomi, kesehatan dan kemitraan.
\end{abstract}

Kata Kunci: COVID-19, Pengabdian Masyarakat, Sustainable Development Goals.

\section{Abstract}

The COVID-19 pandemic situation is directly affecting both the health and economic sectors, especially in Indonesia. The synergy between university, community, and practitioner is needed as an effort for COVID-19 prevention and to help driving the economical sector in terms of the community service program. Sustainable development goals (SDGs) are the global actions that will be referred to as the community service program. The indicator analysis between global action and the outcomes of the community service program is performed to give further the recommendation related to the globally oriented program on solving a local problem. As a scheme of university tri dharma, SGDs based community service program has been implemented to the COVID-19 affected region, namely, a small business of convection in Wedi, Klaten, and health equipment distribution towards Wonosari hospital (RSUD). Program is evaluated in terms of ethical, social and economical dimension, yet the result intepretation is presented as well. The results of these activities have achieved 
the collaboration of community service activities with the mission of the SDGs on the implementation of the economy, health, and partnership sectors.

Keywords : COVID-19, Community Service, Sustainable Development Goals.

\section{Pendahuluan}

Sustainable development goals (SDGs) merupakan hasil kesepakatan para pemimpin dunia akan rencana aksi global yang bertujuan untuk mengakhiri kemiskinan, mengurangi kesenjangan dan melindungi lingkungan. Adapun SDGs berisikan 17 tujuan dan 169 target yang diharapkan akan dapat terpenuhi pada tahun 2030 [1-4] sebagaimana ditunjukkan pada Gambar 1. Lingkup SDGs ialah memaksimalkan siergitas antara target dan implementasi dalam skala orientasi global hingga skala kecil $[5,6]$.

Perguruan tinggi dengan konsep tridharma perguruan tinggi memiliki sebuah wujud pengabdian masyarakat dalam rangka mendukung integrasi penerapan nilai-nilai pengajaran dan penelitian guna memberikan kebermanfaatan langsung kepada masyarakat [7-9]. Berdasarkan pada kedua hal tersebut, dengan sinergitas global berbasis SDGs dan aksi nyata wujud tridharma perguruan tinggi [9], kegiatan pengabdian masyarakat akan memiliki arah yang lebih terstruktur dengan konsep keberlanjutan $[10,11]$.

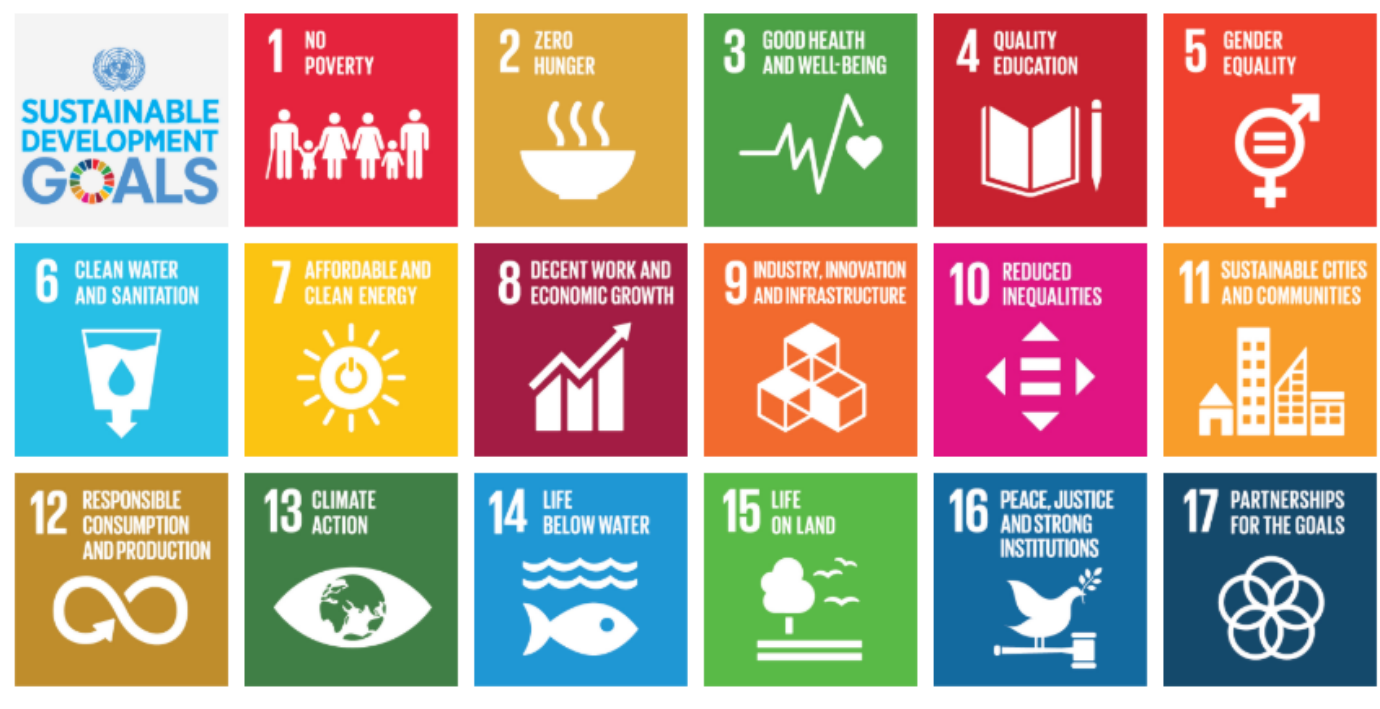

Gambar 1. Program Sustainable Development Goals [1].

Pandemi COVID-19 yang melanda dunia, dan khususnya Indonesia, telah memberikan dampak langsung baik dalam bidang medis dan kesehatan maupun kondisi perekonomian yang berpotensi akan menuju tahapan resesi [12]. Selain itu, kondisi kelangkaan dan tingginya harga alat perlindungan medis seperti masker dan hand-sanitizer menjadi sebuah masalah baik bagi masyarakat maupun tenaga medis. Pada kondisi lain, ekonomi menjadi lesu akibat COVID-19 dan berdampak kepada semua sektor termasuk UMKM. Industri konveksi skala rumahan/UMKM di Wedi, Klaten menjadi salah satu yang terdampak. Diperlukan suatu solusi dimana konveksi tersebut beralih menjadi produsen masker kain dengan standar WHO. Di sisi lain, proses distribusi alat perlindungan tersebut perlu dilakukan ke daerah atau fasilitas yang memiliki dampak paling besar yakni rumah sakit. Sehingga, diperlukan sinergitas antara perguruan tinggi, masyarakat (UMKM) dan praktisi (tenaga medis) untuk upaya pencegahan COVID-19 dan meningkatkan nilai ekonomi dalam bentuk kegiatan pengabdian masyarakat. SDGs akan dijadikan acuan bentuk kegiatan pengabdian masyarakat untuk kemudian dianalisis agar tercapainya tujuan global dan untuk mengarahkan bentuk kegiatan agar lebih baik. Sebagai wujud bentuk pengabdian masyarakat 
dan berlandaskan pada arah aksi global, diperlukan sinergitas antara perguruan tinggi, masyarakat dan praktisi guna untuk menyelesaikan masalah akibat pandemi COVID-19. Berdasarkan hal-hal tersebut, program pengabdian masyarakat akan difokuskan pada isu prioritas SDGs yakni:

1. Kesehatan yang baik dan kesejahteraan dalam menangani kasus COVID 19.

2. Penghapusan kemiskinan dan mengakhiri kelaparan dengan terwujudnya pekerjaan yang layak dan meningkatnya pertumbuhan ekonomi.

3. Jalinan kemitraan antar lembaga untuk mencapai tujuan.

Sehingga, berdasarkan analisis situasi dilingkungan mitra maka dirumuskan beberapa permasalahan prioritas yang akan diselesaikan antara lain:

1. Terdampaknya kondisi ekonomi akibat adanya pandemi COVID-19 yang mengakibatkan kesejahteraan masyarakat menurun.

2. Kelangkaan masker dan hand-sanitizer sebagai sarana terdepan upaya pencegaan COVID-19.

3. Diperlukannya kemitraan antara akademisi, masyarakat dan praktisi medis dalam usaha bersama menanggulangi COVID-19.

\section{Metode}

\subsection{Metode Pelaksanaan}

Berdasarkan pada latar belakang dan analisis situasi, solusi program pengabdian masyarakat yang ditawarkan untuk mengatasi permasalahan ditunjukkan dengan diagram proses pada gambar 2 .

Adapun penjelasan diagram proses sebagai berikut:

1. Perumusan dan analisis masalah

Rumusan dan analisis masalah yang akan diangkat akan disesuaikan dengan pemsalahan lokal serta menghubungkannya dengan program SDGs. Dari analisis tersebut akan ditentukan masalah yang selaras antara permasalahan lokal dan global untuk kemudian diberikan solusi melalui program pengabdian masyarakat.

2. Penentuan lokasi

Lokasi yang dipilih adalah Wedi, Klaten untuk mitra UMKM produksi masker. Sedangkan mitra RSUD akan dipilih RSUD Wonosari. Pertimbangan pemilihan kedua tempat tersebut berdasarkan pembagian wilayah terdampak COVID-19 di DIY dan sekitarnya. Program disini akan difokuskan ke UMKM konveksi Wedi, Klaten dan distribusi alat kesehatan ke RSUD Wonosari.

3. Sumber Daya Manusia (SDM) dan kemitraan

Metode yang dipilih untuk memenuhi kebutuhan SDM yakni dengan melakukan pendataan terhadap kelompok UKM pembuatan masker di Wedi, Klaten serta mencari mitra produksi hand-sanitizer. Mitra untuk kerjasama dengan tenaga medis dilakukan dengan melaksanakan perjanjian kerjasama bersama RSUD Wonosari untuk memberikan edukasi kepada masyarakat mengenai upaya pencegahan COVID-19 dan sebagai sarana penyaluran masker dan hand-sanitizer.

4. Proses produksi

Pendampingan dan proses pengadaan oleh pelaksana pengabdian masyarakat kepada kelompok UKM pembuatan masker dan produksi hand-sanitizer. Dilanjutkan dengan pendampingan serta survei ke RSUD Wonosari mengenai kebutuhan alat pelindung diri medis yang dibutuhkan. Produk yang dihasilkan adalah alat kesehatan dan kelompok UMKM yang memiliki pengetahuan tentang penyebaran Covid-19 dan dapat melakukan pencegahan dengan cara membuat dan memakai masker yang baik dan dapat mendukung kinerja petugas medis di RSUD Wonosari. 


\section{Analisis dan evaluasi program}

Setelah melakukan proses pengabdian, dilanjutkan dengan diskusi untuk mengetahui sejauh mana peningkatan pemahaman cara untuk memutus penyebaran covid-19 dengan pembuatan masker dan penyaluran alat kesehatan untuk mendukung upaya preventif COVID19 di wilayah Wonosari. Analisis program pengabdian berbasis SDG dilakukan setelah proses kegiatan pengabdian dilakukan.

\subsection{Asesmen keberlanjutan}

Pada penelitian ini, program pengabdian masyarakat akan dievaluasi menggunakan asesmen keberlanjutan mengacu pada jurnal Claude et al [13]. Pada asesmen ini, langkah singkat evaluasi akan ditunjukkan pada diagram alir gambar 3. Cakupan program kajian akan ditentukan dan pada penelitian ini cakupan kajian akan dikerucutkan menjadi dimensi ethical, social dan economical. Pada pembobotan nilai akan ditentukan 5 skala dimana nilai 1 adalah tidak didapati kesesuaian antara tujuan dan hasil dan nilai 5 didapatkan sangat kesesuaian. Tahapan evaluasi dan intepretasi mencakup evaluasi hasil penilaian dan intepretasi hasil.

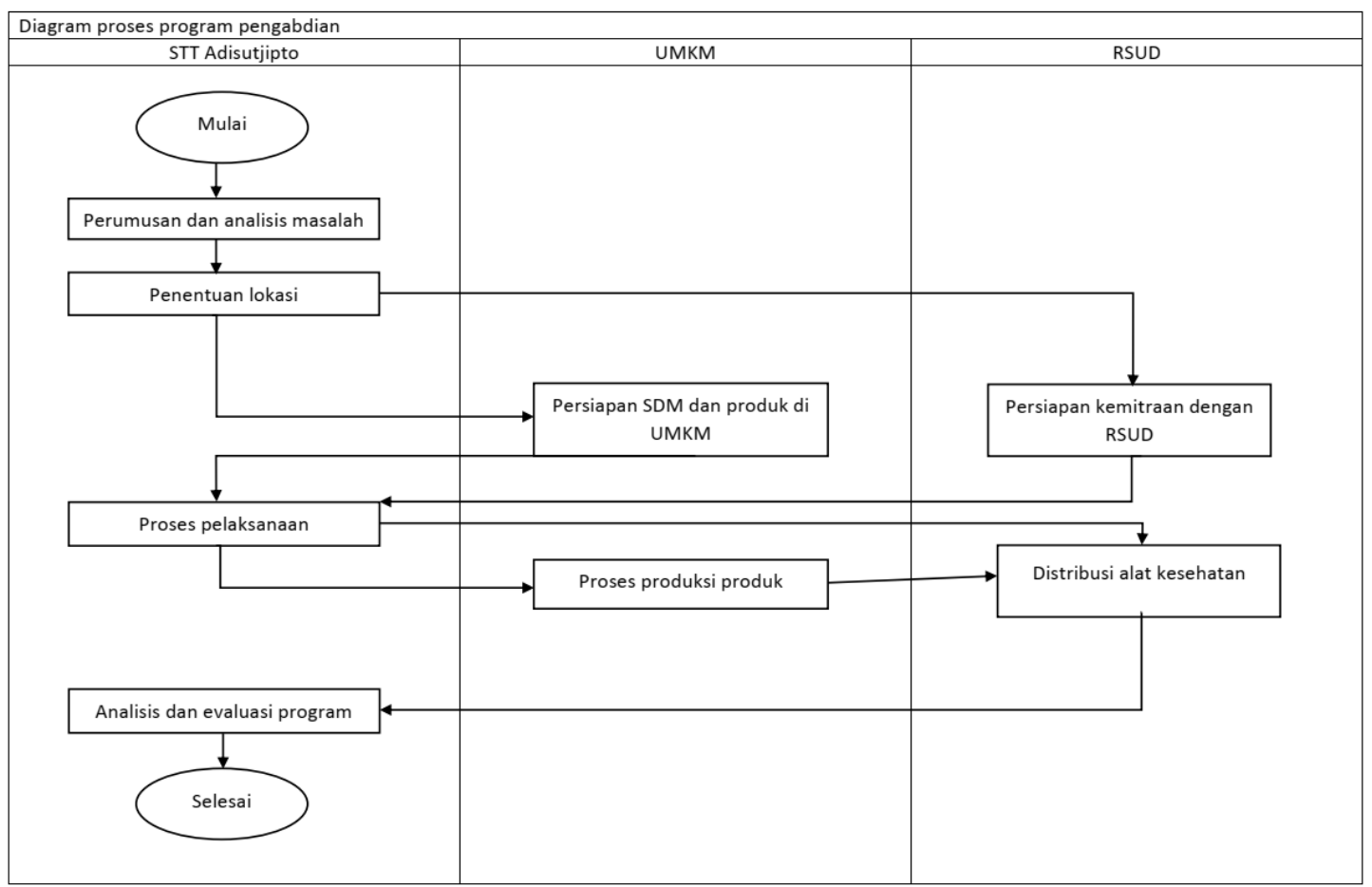

Gambar 2. Diagram proses program pengabdian masyarakat.

\subsection{Target Luaran}

Luaran yang diharapkan dari kegiatan pengabdian kepada masyarakat pada usulan ini adalah tercapainya progam pengabdian masyarakat berbasis SDG dengan rincian sebagai berikut:

1. Tercapainya tujuan penghapusan kemiskinan dan kelaparan (no poverty and zero hunger) melalui perputaran roda perkonomian.

2. Tercapainya tujuan kesehatan dan kesejahteraan (good health and well-being) dengan program penyediaan masker dan hand-sanitizer serta edukasinya ke masyarakat luas.

3. Tercapainya tujuan pekerjaan yang layak dan pertumbuhan ekonomi (decent work and economic growth) dengan stimulasi penghidupan industri rumahan/UMKM pada saat kondisi ekonomi global turun. 
Implementasi Visi Sustainable Development Goals(SDGs) Pada Program Berbasis Masyarakat ...

4. Tercapainya tujuan kemitraan (partnership for the goals) dalam sinergitas penanganan COVID-19.

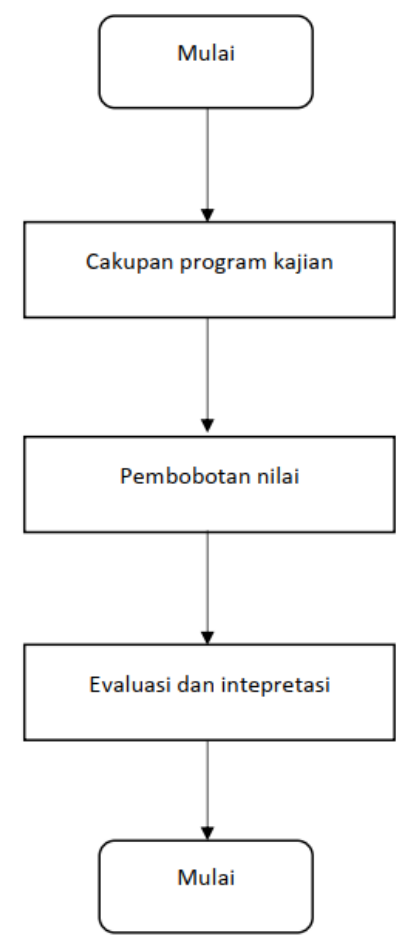

Gambar 3. Diagram alir evaluasi program

\subsection{Gambaran Iptek}

Gambaran iptek yang diberikan kepada mitra ditunjukan pada Gambar 4.
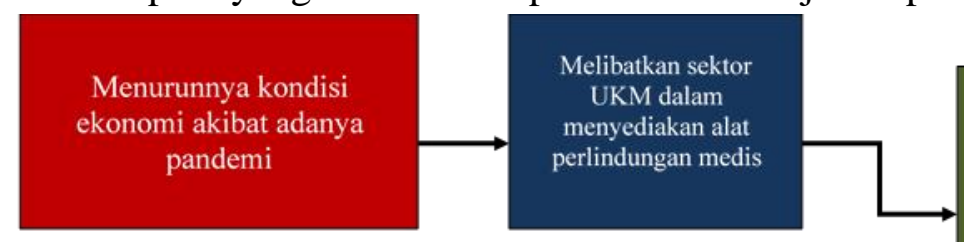

Peningkatan pengetahuan

Kelompok UKM untuk

peningkatan pemahaman cara

untuk memutus penyebaran

covid-19 dengan pembuatan

masker yang baik serta

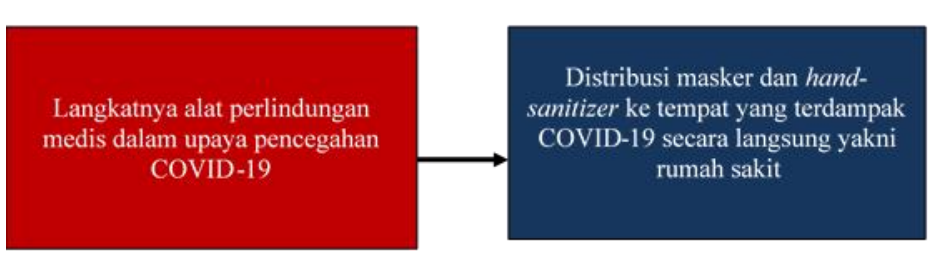

penyaluran ke RSUD Wonosari

- Pemahaman pengetahuan tentang bahaya Covid-19

Kemampuan kelompok UKM untuk peningkatan pemahaman cara untuk

memutus penyebaran covid-19 dengan pembuatan masker yang baik.

- Penyaluran masker ke RSUD Wonosari

Gambar 4. Gambaran iptek kepada mitra 


\section{Hasil dan Pembahasan}

\subsection{Implementasi Kegiatan}

Implementasi kegiatan dilakukan pada 30 April 2020 bertempat di RSUD Wonosari. Dokumentasi kegiatan ditunjukkan pada gambar 5 dan 6. Hubungan antara permasalahan mitra, solusi yang diimplementasikan, dan hasil luaran kegiatan pengabdian dan hubungannya dengan SDGs dirangkum pada Tabel 1.

Tabel 1. Permasalahan, solusi yang ditawarkan dan hasil luaran kegiatan.

\begin{tabular}{|c|c|c|c|}
\hline No. & Permasalahan & Solusi & Hasil Luaran dan SDGs \\
\hline \multicolumn{4}{|c|}{ Bidang Ekonomi } \\
\hline 1 & $\begin{array}{l}\text { Kondisi ekonomi yang } \\
\text { menurun akibat adanya } \\
\text { pandemic COVID-19 yang } \\
\text { berdampak langsung kepada } \\
\text { industry konveksi skala kecil } \\
\text { dan UMKM di Wedi, Klaten, } \\
\text { Jawa Tengah. }\end{array}$ & $\begin{array}{l}\text { Pembelian masker kain skala } \\
\text { industri rumahan dari } \\
\text { pengusaha UMKM konveksi } \\
\text { serta mempromosikan industri } \\
\text { tersebut ke masyarakat dan } \\
\text { daerah/fasilitas RSUD } \\
\text { Wonosari yang terdampak } \\
\text { langsung COVID-19. }\end{array}$ & $\begin{array}{l}\text { Berputarnya kembali roda } \\
\text { perekonomian pada } \\
\text { UMKM konveksi serta } \\
\text { memberikan sarana } \\
\text { pemasaran produk } \\
\text { sehingga diharapkan } \\
\text { meningkatkan } \\
\text { kesejahteraan dalam } \\
\text { rangka penghapusan } \\
\text { kemiskinan dan kelaparan. }\end{array}$ \\
\hline \multicolumn{4}{|c|}{ Bidang Kesehatan } \\
\hline 2 & $\begin{array}{l}\text { Masyarakat dan tenaga } \\
\text { kesehatan memerlukan masker } \\
\text { dan hand-sanitizer untuk } \\
\text { melakukan upaya preventif } \\
\text { penyebaran COVID-19 dimana } \\
\text { harga kedua barang tersebut di } \\
\text { pasaran sangat tinggi. }\end{array}$ & $\begin{array}{l}\text { Pembagian masker dan hand- } \\
\text { sanitizer ke lokasi-lokasi } \\
\text { strategis yang sangat } \\
\text { terdampak dan rawan COVID- } \\
\text { 19, dalam kasus ini adalah } \\
\text { RSUD Wonosari. }\end{array}$ & $\begin{array}{l}\text { Tercapainya tujuan } \\
\text { kesehatan dalam upaya } \\
\text { preventif persebaran } \\
\text { COVID sehingga } \\
\text { kesejahteraan masyarakan } \\
\text { dapat meningkat. }\end{array}$ \\
\hline \multicolumn{4}{|c|}{ Bidang Kemitraan } \\
\hline 3 & $\begin{array}{l}\text { Perlu adanya sinergitas antara } \\
\text { akademisi-praktisi-masyarakat } \\
\text { dalam upaya penganggulangan } \\
\text { COVID-19 }\end{array}$ & $\begin{array}{l}\text { Program kerjasama mitra } \\
\text { antara perguruan tinggi, } \\
\text { tenaga medis (rumah sakit) } \\
\text { dan pelaku industri } \\
\text { rumahan/UMKM untuk } \\
\text { memberikan edukasi } \\
\text { mengenai COVID-19 dan } \\
\text { membantu dalam } \\
\text { menyediakan masker dan } \\
\text { hand-sanitizer. }\end{array}$ & $\begin{array}{l}\text { Terciptanya kemitraan dan } \\
\text { kerjasama dalam upaya } \\
\text { penanggulanan COVID-19 } \\
\text { serta teredukasinya } \\
\text { masyarakat. }\end{array}$ \\
\hline
\end{tabular}

Berdasarkan pembahasan hubungan antara permasalahan, solusi dan hasil luaran yang didapatkan dapat dikatakan bahwa program pengabdian masyarakat yang dilakukan telah sesuai dengan misi SDGs. Dengan adanya acuan misi SDGs program dapat terlaksana dengan 
menyelesaikan masalah lokal dengan misi global. Hal ini dapat memberikan gambaran bahwasanya program-program pengabdian dapat dilaksanakan tidak hanya dengan orientasi penyelesaian masalah dan transfer pengetahuan, akan tetapi juga bisa selaras dengan mendukung misi global SDGs. Selain itu, program pengabdian juga memberikan transfer iptek dan isu terkini terkait dengn COVID-19 kepada masyarakat dan membentuk relasi [9].

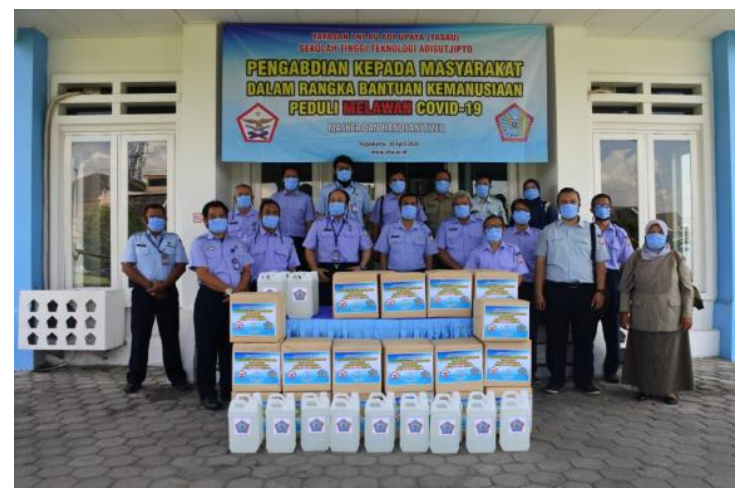

Gambar 5. Dokumentasi tim pengabdian masyarakat STT Adisutjipto.

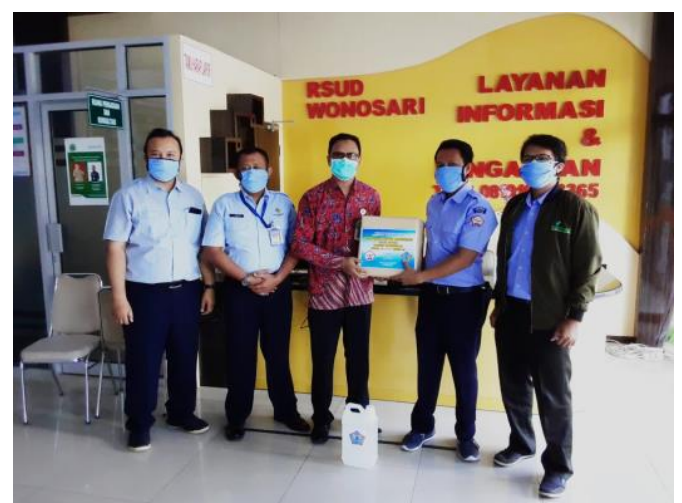

Gambar 6. Dokumentasi simbolis penyerahan hand-sanitizer dan masker ke RSUD Wonosari.

\subsection{Evaluasi asesmen keberlanjutan}

Program pengabdian masyarakat yang telah dilakukan akan dievaluasi dalam cakupan 3 dimensi yakni ethical, social dan economy.

\subsubsection{Ethical}

Evaluasi pada dimensi ethical mencakup penghapusan kemiskinan, adanya restorasi dan kompensasi dan tumbuhnya solidaritas. Ditampilkan pada gambar 7, masing-masing komponen akan diberikan penilaian sesuai dengan tujuan SGDs dan implementasi program pengabdian. Dalam program pengabdian yang telah dilakukan, nilai penghapusan kemiskinan akan diberikan poin 3 dimana proses produksi masker dan distribusi tidak serta merta dapat menghapuskan kemiskinan. Selain itu, program ini belum dirancang untuk jangka panjang dan bersifat insidental akibat pandemi dan lesunya ekonomi. Dari sisi restorasi dan kompensasi, dalam praktek program ini restorasi dan kompensasi ekonomi tidak diberikan dalam bentuk pemberian tunai melainkan dalam bentuk kerjasama. Kerjasama mitra antara produsen konveksi, perguruan tinggi, rumah sakit dan masyarakat adalah sarana agar roda ekonomi tetap bisa berjalan dan aspek keamanan kesehatan dapat dicapai. Pada hal ini, akan diberikan poin 3 karena pada prakteknya program yang dilakukan masih merupakan langkah awal. Dalam aspek solidaritas, kerjasama mitra dalam program pengabdian akan memberikan sinergitas yang baik dalam perputaran ekonomi dan bidang kesehatan dalam bentuk produksi masker dan distribusinya ke masyarakat melalui rumah sakit. 


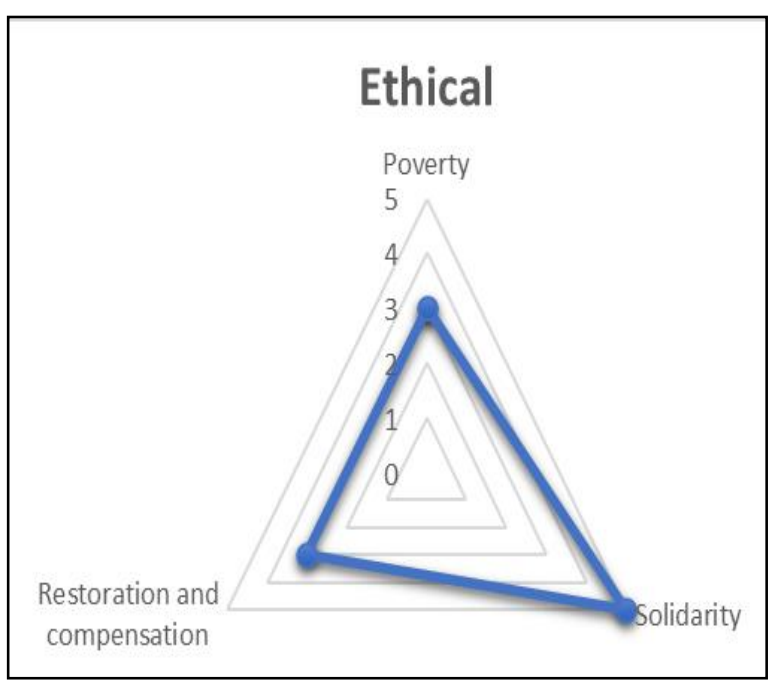

Gambar 7. Hasil evaluasi dimensi ethical.

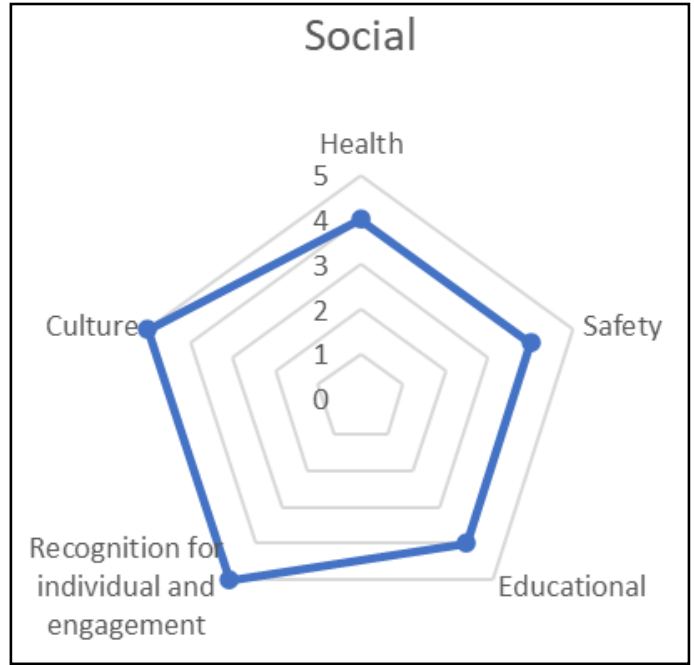

Gambar 8. Hasil evaluasi dimensi social.

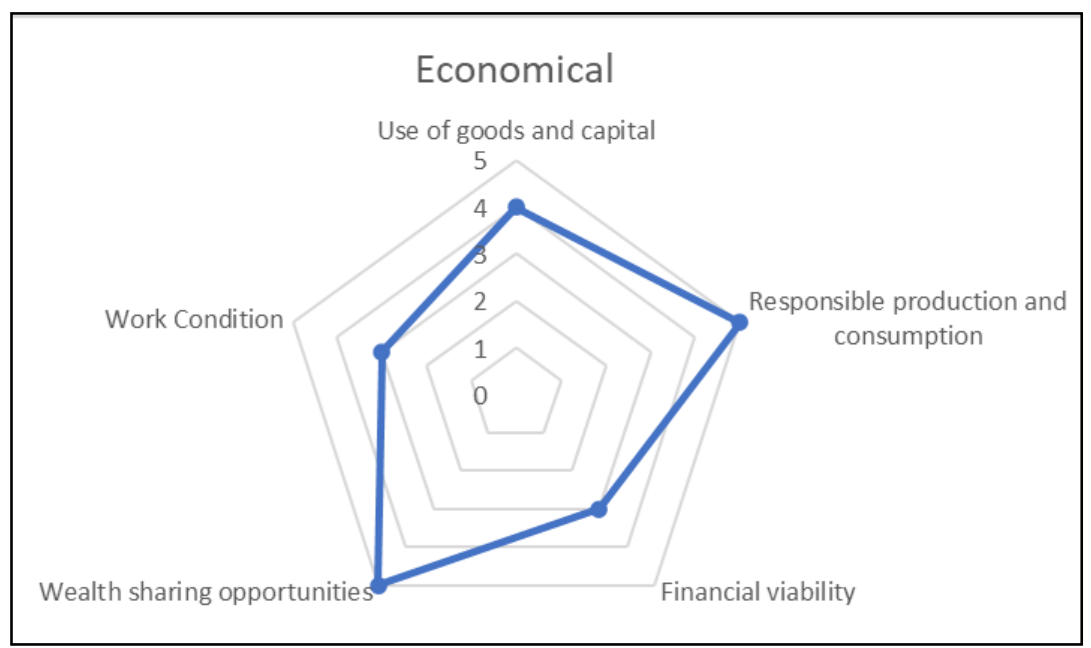

Gambar 9. Hasil evaluasi dimensi economical.

\subsubsection{Social}

Evaluasi bidang social akan melibatkan tercapainya aspek kesehatan, budaya, keikutsertaan masyarakat, edukasi dan keselamatan sebagaimana ditunjukkan pada Gambar 8 Aspek budaya dan keterlibatan dan keikutsertaan individu masyarakat akan diniliai tinggi karena program ini melibatkan kerjasama mitra untuk mencapai tujuan perputaran ekonomi dan kesehatan. Budaya gotong royong dan saling menolong terwujud dalam pelaksanaan program. Selain itu, dalam pelaksanaanya juga diselipkan edukasi mengenai COVID-19 ke masyarakat. Meski edukasi tidak dikhususkan dalam pelaksanaanya, namun penyisipan aspek edukasi kesehatan mengenai COVID-19 pada pelaksanaan produksi masker, hand sanitizer dan distribusinya dinilai cukup efektif. Distribusi alat kesehatan yang dibarengi dengan edukasi tersebut dapat dikatakan selaras dengan dimensi social dari aspek ketercapainya kesehatan dan keamanan di masyarakat dalam konteks aksi preventif penyebaran COVID-19. 
Implementasi Visi Sustainable Development Goals(SDGs) Pada Program Berbasis Masyarakat ...

\subsubsection{Economy}

Gambar 9 menunjukkan hasil evaluasi dimensi economical. Evaluasi ini akan melibatkan komponen penggunaan barand dan modal, kajian kondisi kerja, kesempatan berbagi, kelangsungan finansial dan tanggungjawab produksi dan konsumsi. Produksi masker dan hand sanitizer skala UMKM akan menggunakan bahan-bahan lokal yang tersedia namun dilakukan standarisasi berbasis WHO. Hal ini dinilai baik karena dapat memanfaatkan barang sekitar sehingga modal juga bisa ditekan. Kesempatan berbagi dalam program ini sangat terbuka dimana dalam wujud kemanusiaan, kerjasama antar mitra dalam produksi masker dan hand sanitizer serta distribusinya melibatkan pihak-pihak yang secara sukarela berbagi. Dengan adanya kerjasama mitra, produksi dan konsumsi dalam wujud distribusi dapat terlaksana sehingga dari segi tanggung jawab produksi dan konsumsid apat tercapai dengan sangat baik. Kami menilai lingkungan kerja tidak cukup baik, hal ini disebabkan akibat pandemi maka perlu diberlakukan protokol kesehatan dan upaya-upaya preventif sehingga secara langsung mempengaruhi proses produksi. Dari segi keberlangsungan finansial, karena program pengabdian ini merupakan hanya langkah awal dan akibat adanya pandemi yang tidak dapat diprediksi sehingga keberlangsungan finansial belum dapat dipastikan.

\section{Kesimpulan}

Berdasarkan kegiatan pengabdian masyarakat berbasis SDGs yang telah dilaksanakan dan dievaluasi, telah terwujud keselarasan program dengan tercapainya tujuan:

1. No poverty and zero hunger serta decent work and economic growth dengan berputarnya kembali roda perekonomian pada UMKM konveksi berikut pelayanan sarana pemasaran produk.

2. Good health and well-being dalam upaya preventif persebaran COVID-19 sehingga kesejahteraan masyarakan dapat meningkat.

3. Partnership for the goals dengan kerjasama perguruaan tinggi dalam upaya penanggulanan COVID-19 bersama dengan masyarakat dan praktisi.

\section{Daftar Pustaka}

[1] United "Sustainable development goals", https://sustainabledevelopment.un.org/?menu=1300 [diakses pada 6 Mei 2020].

[2] Sustainable development goals Indonesia, "Sustainable development goals", https://www.sdg2030indonesia.org/ [diakses pada 6 Mei 2020]

[3] Prajal Pradhan, Luis Costa, Diego Rybski, Wolfgang Lucht, Juergen P. Kropp, “A Systematic Study of Sustainable Development Goal (SDG) Interactions”, Earth's Future, 5, 1169-1179, 2017.

[4] Jeffrey D Sachs, "From Millenium Development Goals to Sustainable Developmet Goals", Lancet, 2012

[5] Jan Servaes (Editor), "Sustainable Development Goals in the Asian Context", Springer, 2017

[6] David Griggs, "Sustainable Development Goals for People and Planet" ,Nature, Macmillan Publishers, 2013.

[7] RistekBRIN, "Memperkuat peran tinggi", https://www.ristekbrin.go.id/kolom-opini/memperkuat-peran-perguruan-tinggi/ [diakses 7 Mei 2020]. 
[8] Undang-Undang Nomor 12 Tahun 2012 tentang Pendidikan Tinggi

[9] Yos Johan Utama, Ambariyanto, Muhammad Zainuri, Darsono, Budi Setyono, Widowati, Sapto Purnomo Putro, "Sustainable Development Goals as the Basis of University Management Towards Global Competitiveness", IOP Conf. Series: Journal of Physics, 2018.

[10] Ishartono, Santoso Tri Raharjo, "Sustainable Development Goals (SDGs) dan Pengentasan Kemiskinan”, Jurnal BPPK, Volume 6 no 2, 2016

[11] Terry Porter, Jose Cordoba, "Three Views of Systems Theories and Their Implications for Sustainability Education”, Journal of Management Education, 2009.

[12] A20 MOODY'S ANALYTICS- A Briefing Exclusively for Indonesia, April 2020

[13] Claude Villeneuve, David Tremblay, Olivier Riffon, Georges Y. Lanmafankpotin, Sylvie Bouchard, "A Systemic Tool and Process for Sustainability Assessment", Sustainability MDPI, 2017. 